\title{
Hubungan tingkat kontrol dengan arus puncak ekspirasi pada pasien asma
}

\author{
Nur Anniesa Indayani Imran ${ }^{1}$ Rita Khairani ${ }^{2}$ Febrina Susanti ${ }^{3}$
}

\begin{abstract}
ABSTRAK
\section{LATAR BELAKANG}

Asma adalah penyakit heterogen, yang ditandai dengan peradangan jalan napas kronik dan masih menjadi masalah kesehatan di semua negara. Menurut data Riskesdas 2013 prevalensi asma di Indonesia mencapai $4.5 \%$. Pada pasien asma, obat pelega jangka pendek dan pengontrol jangka panjang digunakan untuk mempertahankan asma dalam keadaan terkontrol. Tingkat kontrol asma dapat dinilai secara subjektif dengan menggunakan kuisioner tingkat kontrol spesifik dan secara obyektif dengan pengukuran fungsi paru salah satunya arus puncak ekspirasi. Penelitian ini bertujuan untuk mengetahui hubungan tingkat kontrol asma dengan arus puncak ekspirasi pada pasien asma.
\end{abstract}

\section{METODE}

Penelitian ini menggunakan desain potong lintang. Sampel berjumlah 57 orang menggunakan consecutive non random sampling. Pengambilan data dilakukan pada bulan November-Desember 2017. Data untuk menilai tingkat kontrol diperoleh dengan kuesioner ACT dan data fungsi paru menggunakan peak flow meter untuk mengukur arus puncak ekspirasi. Analisis statistik menggunakan uji chi-square dengan tingkat kemaknaan $\mathrm{p}<0.05$.

\section{HASIL}

Sebanyak $82.5 \%$ pasien dengan asma tidak terkontrol dan $86 \%$ dengan arus puncak ekspirasi berada di zone merah. Tidak terdapat hubungan bermakna tingkat kontrol asma dengan arus puncak ekspirasi pada pasien asma $(\mathrm{p}=0.137)$.

\section{KESIMPULAN}

Tidak terdapat hubungan bermakna tingkat kontrol asma dengan arus puncak ekspirasi pada pasien asma.

Kata kunci : asma, tingkat kontrol asma, arus puncak ekspirasi

\author{
${ }^{1}$ Program Studi Kedokteran, \\ Fakultas Kedokteran, \\ Universitas Trisakti \\ ${ }^{2}$ Departemen Ilmu Penyakit Dalam, \\ Fakultas Kedokteran, \\ Universitas Trisakti \\ ${ }^{3}$ Departemen Pulmonologi, RSUD \\ Budhi Asih
}

\section{Korespondensi:}

Rita Khairani

Departemen Ilmu Penyakit Dalam, Fakultas Kedokteran Universitas

Trisakti, Jalan Kyai Tapa No. 260, Grogol, Jakarta Barat.

Telp. : +6282124004364

Email: rita.khairani@trisakti.ac.id

J Biomedika Kesehat 2018;1(2):152-

157

DOI : 10.18051/JBiomedKes.2018.

v1.152-157

pISSN: 2621-539X / eISSN: 2621-5470

Artikel akses terbuka (open access) ini didistribusikan di bawah lisensi Creative Commons Attribution 4.0 International (CC-BY 4.0) 


\section{ABSTRACT}

\section{Relationship between level of control and peak expiratory flow in asthma patients}

\section{BACKGROUND}

Asthma is a heterogeneous disease that usually characterized by chronic airway inflammation and remain a health problem in every country. According to data of Riskesdas 2013, the prevalence of asthma in Indonesia reached $4.5 \%$. Asthma patients usually use short- acting medication for their reliefs, and long acting medication to control their asthma. The level of asthma control can be rated subjectively by using specific control level questionnaire and objectively monitored by the lung function measurement using a peak expiratory flow rate. The goal of this study were to investigate the relationship between level of control and peak expiratory flow in asthma patients.

\section{METHODS}

This study used a cross sectional design. There were 57 samples and obtained by consecutive non random sampling. This study was done on November-December 2017. The data to asses asthma control level by questionnaires ACT and lung function was determined by peak expiratory flow measurements using a peak flow meter. Statistical analysis using Chi-square test with significancy $\mathrm{p}<0.05$.

\section{RESULT}

There is $82.5 \%$ patients has uncontrolled asthma and $86 \%$ has peak expiratory flow rate on red zone. There is no a significant association between level of control and peak expiratory flow rate $(p=0.137)$.

\section{CONCLUSION}

There is no significant correlation between level of control and peak expiratory flow in asthma patients.

Keywords : asthma, the level control of asthma, peak expiratory flow

\section{PENDAHULUAN}

Asma adalah penyakit heterogen, biasanya ditandai dengan peradangan jalan napas kronik. Asma didefinisikan sebagai riwayat gejala pernafasan seperti mengi, sesak napas, nyeri dada dan batuk yang bervariasi dari waktu dan intensitasnya, bersamaan dengan keterbatasan aliran udara ekspirasi yang bervariasi. $^{(1)}$ Asma masih menjadi masalah kesehatan di semua negara dan diderita oleh anak-anak sampai dewasa dengan derajat penyakit ringan sampai berat bahkan beberapa kasus dapat menyebabkan kematian. ${ }^{(2)}$ World Health Organization (WHO) memperkirakan terdapat 235 juta orang yang saat ini mengidap asma dan jumlahnya diperkirakan akan terus bertambah. Menurut perkiraan WHO tahun 2016, terdapat 383.000 kematian akibat asma pada tahun 2015. Apabila tidak dicegah dan ditangani dengan baik, maka diperkirakan terjadi peningkatan prevalensi di masa yang akan datang. ${ }^{(2,3)}$

Menurut data Riskesdas 2013, di Indonesia prevalensi asma mencapai $4.5 \%$. $^{(2)}$ Pasien asma, selain menggunakan obat jangka pendek untuk melegakan, juga diharuskan menggunakan obat jangka panjang setiap hari untuk mempertahankan asma dalam keadaan terkontrol. ${ }^{(4)}$ Kuesioner tingkat kontrol spesifik terhadap asma telah dikembangkan dan divalidasi sehingga dapat menyeleksi asma yang tidak terkontrol, mengubah pengobatan yang tidak efektif menjadi lebih tepat, melaksanakan pedoman pengobatan secara lebih tepat, dan memberikan pendidikan atau pengetahuan tentang bahaya asma yang tidak terkontrol. ${ }^{(5)}$ Beberapa kuesioner sudah dipublikasikan antara lain Asthma Control Test (ACT), Asthma Control Questionnaire (ACQ), dan Asthma Control Scoring System $(\mathrm{ACS}){ }^{(6)}$

Manajemen asma yang tepat sangat bergantung pada kemampuan pasien memonitor gejala asma secara teratur. Pasien yang sudah terkontrol dengan baik perlu dipantau dari waktu ke waktu untuk menilai kembali tingkat keparahan asma dan menyesuaikan obat sesuai kebutuhan. Pemantauan diri tidak hanya melibatkan penilaian frekuensi dan tingkat keparahan gejala tetapi juga pengukuran fungsi paru, yang sering dilakukan dengan mengukur peak expiratory flow (PEF). ${ }^{(7)}$

Penelitian yang dilakukan oleh Mendoza $\mathrm{dkk}^{(8)}$, pada 86 pasien asma dalam penelitian kohort prospektif mendapatkan hubungan bermakna antara tingkat kontrol asma menggunakan ACT dengan arus puncak 
ekspirasi (APE). Mendoza dkk membagi ACT dalam dua kategori, bila nilai ACT yang didapatkan $>19$ maka termasuk dalam kategori terkontrol dan nilai ACT $<19$ maka termasuk dalam kategori tidak terkontrol. Pada ACT terkontrol di dapatkan APE prediksi $>80 \%$, sedangkan pada ACT tidak terkontrol di dapatkan APE prediksi $<80 \%{ }^{(8)}$ Penelitian yang dilakukan Ilyas $\mathrm{dkk}^{(9)}$ di poliklinik asma RS Persahabatan Jakarta, mendapatkan korelasi lemah $(\mathrm{r}=0.298) \quad \mathrm{p}=0.003$ antara ACT dengan APE. ${ }^{(9)}$ Berbagai penelitian sudah dilakukan untuk mengetahui hubungan tingkat kontrol asma dan arus puncak ekspirasi dengan hasil berbeda. Hal ini yang melatarbelakangi peneliti untuk melakukan penelitian yang bertujuan untuk mengetahui hubungan tingkat kontrol asma dan arus puncak ekspirasi pada pasien asma persisten usia 18-60 tahun.

\section{METODE}

Penelitian ini dilaksanakan di poliklinik paru RSUD Budhi Asih Cawang, Jakarta Timur, pada bulan NovemberDesember 2017. Penelitian ini menggunakan desain penelitian potong lintang. Besar sampel penelitian ini berjumlah 57 orang diperoleh dari rumus infinit $n_{0}=\left(z^{2} \times p \times q\right) / d^{2}$. Tingkat kemaknaan (z) 1.96, prevalensi asma (p) $5.2 \%{ }^{10}$ dan $\mathrm{d}=0.01$, dilanjutkan dengan rumus finit $\mathbf{n}=\left(\underline{\mathrm{n}}_{0} /\left(1+\left(\mathrm{n}_{0} / \mathrm{N}\right)\right) . \mathrm{N}\right.$ adalah besar populasi finit yang diambil dari jumlah pasien asma di Poliklinik Paru di RSUD Budhi Asih Cawang, Jakarta Timur yaitu 115 pasien.

Subjek penelitian dipilih secara non probability consecutive sampling dengan kriteria inklusi yaitu pasien asma yang menggunakan obat inhaler jangka panjang minimal 6 bulan, berusia 18-65 tahun, dapat melakukan perasat APE dan bisa berkomunikasi dengan baik. Kriteria eksklusi adalah pasien asma yang menderita penyakit kronik seperti gagal jantung, gagal ginjal kronik dan penyakit hati kronik dan tidak pernah menderita TB paru, untuk menyingkirkan penyebab sesak selain asma.

Penelitian ini menggunakan data primer yaitu hasil pengisian kuesioner dan pemeriksaan arus puncak ekspirasi. Instrumen yang digunakan: adalah kuesioner tingkat kontrol asma dengan menggunakan ACT. Kuesioner ini terdiri dari lima pertanyaan, yang masingmasing bernilai maksimal 5, kemudian dikategorikan menjadi asma terkontrol bila didapatkan skor 20-25, atau tidak terkontrol bila didapatkan skor $\leq 19$. ${ }^{(6)}$. Pengukuran arus puncak ekspirasi dengan menggunakan peak flow meter, dinilai persentase hasil terbaik dibandingkan dengan prediksi, kemudian dikategorikan menjadi zona merah (APE $<50 \%$ ), zona kuning (APE 50-79\%) dan zona hijau (APE 80-100\%). Penelitian ini telah dinyatakan lolos kaji etik dari komite etik penelitian Fakultas Kedokteran Universitas Trisakti.. Analisis data menggunakan uji Chisquare dengan tingkat kemaknaan 0.05

\section{HASIL}

Tabel 1. Karakteristik subjek penelitian

\begin{tabular}{lcc}
\hline Variabel & n (\%) \\
\hline Jenis Kelamin & 13 & $(22.8)$ \\
Laki-laki & 44 & $(77.2)$ \\
Perempuan & & \\
Usia (Tahun) & 6 & $(10.5)$ \\
$17-25$ & 6 & $(10.5)$ \\
$26-35$ & 18 & $(31.6)$ \\
$36-45$ & 13 & $(22.8)$ \\
$46-55$ & 14 & $(24.6)$ \\
$56-65$ & & \\
Penggunaan Obat & 31 & $(54.4)$ \\
Kombinasi Budesonide \& & 22 & $(38.6)$ \\
Formoterol Fumarate & & \\
Kombinasi Salmeterol \& & 4 & $(7.0)$ \\
Fluticasone Propionate & & \\
Budesonide & 10 & $(17.5)$ \\
Tingkat Kontrol Asma & 47 & $(82.5)$ \\
Terkontrol sebagian & & \\
Tidak terkontrol & 8 & $(14.0)$ \\
Arus Puncak Ekspirasi & 49 & $(86.0)$ \\
Kuning & & \\
Merah & & \\
\hline
\end{tabular}

\section{Penelitian}

ini berhasil mengikutsertakan 57 responden. Karakteristik subjek penelitian dapat dilihat pada Tabel 1 terlihat 44 orang $(77.2 \%)$ berjenis kelamin perempuan lebih banyak dari yang berjenis kelamin laki- laki yaitu sebanyak 13 orang (22.8\%). Usia yang paling dominan adalah kelompok usia 36-45 tahun sebesar 31.6\%. Penggunaan obat kortikosteroid inhaler yang dominan adalah yang menggunakan obat kombinasi budesonide \& formoterol fumarate sebanyak 31 orang $(54.4 \%)$. 
Tabel 2. Hubungan antara tingkat kontrol asma dengan arus puncak ekspirasi

\begin{tabular}{|c|c|c|c|c|}
\hline \multirow[b]{2}{*}{ Tingkat kontrol asma } & \multicolumn{2}{|c|}{ Arus puncak ekspirasi } & \multirow{2}{*}{$\begin{array}{c}\text { Total } \\
\mathbf{n}\end{array}$} & \multirow[b]{2}{*}{ Nilai $\mathbf{p}^{*}$} \\
\hline & $\begin{array}{c}\text { Warna Kuning } \\
\text { n }(\%)\end{array}$ & $\begin{array}{c}\text { Warna Merah } \\
\text { n }(\%)\end{array}$ & & \\
\hline Terkontrol sebagian & $3(30)$ & $7 \quad(70)$ & 10 & \multirow{2}{*}{0.109} \\
\hline Tidak terkontrol & $5(10.6)$ & $42(89.4)$ & 47 & \\
\hline Total & $8(14.0)$ & $49(86.0)$ & 57 & \\
\hline
\end{tabular}

Tingkat kontrol asma responden yang terbanyak adalah asma tidak terkontrol yaitu 47 orang $(82.5 \%)$. Berdasarkan pemeriksaan arus puncak ekspirasi terdapat 49 orang $(86.0 \%)$ yang memiliki arus puncak ekspirasi berada di zona merah 8 orang $(14.0 \%)$ memiliki arus puncak ekspirasi berada di zona kuning.

Tabel 2 memperlihatkan hubungan antara tingkat kontrol asma dengan arus puncak ekspirasi. Hasil uji Chi-Square didapatkan nilai $p=0.137$, sehingga dapat disimpulkan bahwa tidak terdapat hubungan yang bermakna antara arus tingkat kontrol asma dengan arus puncak ekspirasi pada pasien asma.

\section{PEMBAHASAN}

Responden pada penelitian ini lebih banyak berjenis kelamin perempuan sebanyak 44 orang $(77.2 \%)$ dibandingkan laki laki sebanyak 13 orang (22.8\%). Penelitian ini sesuai dengan penelitian yang di lakukan oleh Atmoko dkk ${ }^{(8)}$ yang mendapatkan pasien asma lebih banyak ditemukan pada perempuan sebanyak 69 orang $(64.5 \%)$, dibandingkan dengan laki-laki yang berjumlah 38 orang $(35.5 \%){ }^{(8)}$ Jenis kelamin laki-laki merupakan faktor risiko asma pada anak-anak, namun setelah mencapai masa pubertas prevalensi asma lebih banyak pada perempuan daripada laki-laki. $^{(1)}$

Responden terbanyak pada kelompok usia 36-45 tahun yaitu 18 orang (31.6\%), dan yang paling sedikit pada kelompok usia muda 17-25 tahun dan 26-35 tahun, masingmasing $10.5 \%$. Pada penelitian Priyanto $\mathrm{dkk}^{(9)}$ didapatkan usia responden terbanyak yang menderita asma adalah usia dewasa (70.6\%), usia lanjut (21.6\%), dan remaja $(7.8 \%) .{ }^{(9)}$ Dari beberapa studi diketahui bahwa asma pada masa kanak-kanak tetap dapat bertahan sampai dewasa dan ada juga asma bisa menghilang selama bertahun-tahun tetapi muncul kembali sesuai dengan pertambahan umur. ${ }^{(11)}$

Penggunaan obat asma pada penelitian ini, 31 orang $(54.4 \%)$ menggunakan obat kombinasi budesonide \& formoterol fumarate, 22 orang $(38.6 \%)$ menggunakan obat kombinasi salmeterol \& fluticasone propionate dan 4 orang (7\%) menggunakan obat budesonide. Hal ini sesuai dengan penelitian yang dilakukan oleh Haryanti S dkk, ${ }^{(12)}$ didapatkan kombinasi budesonide dengan formoterol (47\%), diikuti kombinasi salmeterol dengan flutikason $(25 \%){ }^{(12)}$ Pedoman internasional merekomendasikan kombinasi beta 2 agonis kerja lama (LABA) dengan kortikosteroid inhalasi dosis rendahsedang (ICS) bila asma tidak sepenuhnya dikontrol oleh ICS saja sebagai pilihan pengobatan pertama pada asma sedang. Beberapa uji klinis menunjukkan bahwa penambahan LABA ke ICS lebih bermanfaat daripada meningkatkan dosis ICS saja untuk kontrol gejala dan fungsi paru. ${ }^{(13)}$ Salmeterol dan formoterol merupakan $\beta 2$-agonis aksi panjang yang efek anti inflamasi lemah jika diberikan dalam bentuk tunggal. ${ }^{(14)}$

Berdasarkan tingkat kontrol asma di dapatkan responden dengan asma terkontrol sebagian yaitu 47 orang $(82.5 \%)$ dan responden dengan asma yang tidak terkontrol yaitu 10 orang $(17.5 \%)$. Tidak satupun responden dengan asma yang terkontrol penuh. Hal ini serupa dengan penelitian yang dilakukan oleh Priyanto $\mathrm{dkk}^{(9)}$ dengan pemeriksaan tingkat kontrol asma melalui pengisian lembaran kuesioner ACT, didapatkan pasien asma yang tidak terkontrol sebanyak 80 orang $(78.43 \%)$ dan terkontrol sebagian 22 orang $(21.57 \%)$. (9) Penelitian lain dilakukan oleh Bachtiar dkk didapatkan bahwa sebagian besar pasien asma 
tidak terkontrol 230 orang (66.9\%), terkontrol sebagian 113 orang $(33.1 \%)$ dan hanya 1 $(0.1 \%)$ orang pasien asma yang terkontrol penuh. ${ }^{(15)}$ Perbedaan ini dapat disebabkan oleh banyak faktor yang memengaruhi tingkat kontrol asma seperti tingkat kontrol asma saat masih anak-anak dapat memengaruhi morbiditas pada saat dewasa, penggunaan obat yang tidak efektif, rendahnya kepatuhan dalam terapi, paparan alergen lingkungan dan paparan asap rokok, bahkan paparan pasif, karena dapat menyebabkan gejala asma meningkat dan penurunan respons terhadap kortikosteroid inhalasi. $^{(16)}$

Pemeriksaan arus puncak ekspirasi, 49 orang $(86.0 \%)$ yang memiliki arus puncak ekspirasi berada di zona merah, terdapat 8 orang $(14.0 \%)$ yang memiliki arus puncak ekspirasi berada di zona kuning dan tidak ada satupun responden dengan arus puncak ekspirasi berada di zona hijau. Hal ini sesuai dengan penelitian yang dilakukan oleh William dkk yang mendapat sebagian besar arus puncak ekspirasi berwarna merah. (17) Nilai aliran puncak ekspirasi (APE) pada seseorang mencerminkan terjadinya perubahan jalan napas. ${ }^{(1)}$

Analisis dengan uji Chi-Square didapatkan nilai $p=0.137$, sehingga dapat disimpulkan bahwa tidak terdapat hubungan yang bermakna antara tingkat kontrol asma dengan arus puncak ekspirasi pada pasien asma. Hasil penelitian memperlihatkan responden dengan asma tidak terkontrol yang memiliki arus puncak ekspirasi berada di zona merah sebanyak 42 orang $(89.4 \%)$ dan yang memiliki arus puncak ekspirasi berada di zona kuning sebanyak 5 orang $(10.6 \%)$. Sementara responden dengan asma terkontrol sebagian yang memiliki arus puncak ekspirasi berada di zona merah sebanyak 7 orang $(70 \%)$ dan arus puncak ekspirasi berada di zona kuning sebanyak 3 orang (30\%). Hal ini tidak sesuai dengan penelitian yang telah dilakukan oleh Ilyas dkk, dimana dalam analisis penelitian menggunakan uji kolerasi Spearman diperoleh hubungan yang sangat lemah antara ACT dan arus puncak ekspirasi yaitu $\mathrm{r} 0.298), \mathrm{p}=0.003$. $^{(18)}$

Penelitian lain dari Mendoza dkk ${ }^{(19)}$, pada 80 pasien asma dalam penelitian kohort prospektif membagi ACT dalam dua kategori, bila nilai ACT yang di dapatkan $>19$ maka termasuk dalam kategori terkontrol dan nilai ACT <19 maka termasuk dalam kategori tidak terkontrol. Pada ACT 20 didapatkan APE Prediksi $>80 \%$ sedangkan pada ACT $<20$ di dapatkan APE prediksi $<80 \%{ }^{\left({ }^{(19)}\right.}$

Pada penelitian ini tidak terdapat hubungan yang bermakna antara tingkat kontrol asma dan arus puncak ekspirasi. Sebagian besar responden memiliki asma tidak terkontrol dengan arus puncak ekspirasi berada di zona merah sebanyak 42 orang $(89.4 \%)$. Secara umum nilai aliran puncak ekspirasi pasien asma sangat beragam hal tersebut terkait dengan besarnya obstruksi, waktu serangan, dan gejalagejala yang dialami yang kemudian dapat digolongkan atau dikategorikan berdasarkan zona dan besarnya obstruksi. ${ }^{(17)}$ Beberapa faktor dapat memicu terjadinya serangan asma sehingga dapat mempengaruhi arus puncak ekspirasi seperti stres, cuaca, paparan alergen, riwayat merokok dan aktivitas jasmani. Berbagai faktor tersebut dapat menyebabkan bronkospasme yang menghambat pengeluaran secara maksimal ketika melakukan pemeriksaan arus puncak ekspirasi. Nilai arus puncak ekspirasi juga dipengaruhi oleh variasi diurnal dimana arus puncak ekspirasi lebih rendah pada pagi hari dan mencapai puncak pada malam hari. ${ }^{(20)}$

\section{KESIMPULAN}

Berdasarkan hasil penelitian didapatkan $82.5 \%$ responden dengan asma tidak terkontrol, tidak satupun responden dengan asma yang terkontrol penuh. Sebanyak $86.0 \%$ responden berada di zona merah dan tidak terdapat hubungan yang bermakna antara tingkat kontrol asma dengan arus puncak ekspirasi pada pasien asma.

Penelitian ini menggunakan metode desain penelitian studi potong lintang sehingga tidak dapat melihat perjalanan penyakit. Beberapa responden berada pada kelompok usia lansia sehingga terdapat keterbatasan penilaian ACT oleh karena terdapat faktor kesulitan mengingat dari responden. Pengidap 
asma diharuskan melakukan pemeriksaan secara rutin dan menghindari pencetus agar asma selalu terkontrol dan arus puncak ekspirasi berada pada zona hijau.

\section{DAFTAR REFERENSI}

1. Global Initiative for Asthma (GINA). Global strategy for asthma management and prevention. Report, GINA. 2015 [cited 2017 May 4]. Available from: http://ginasthma.org/wp-content/ uploads/2016/01/GINA_Report_2015_Aug11-1. pdf

2. Kementrian Kesehatan RI. Riset Kesehatan Dasar (Riskesdas) 2013. Jakarta; 2013. [cited 2017 May 3]. Available from: http://www.depkes. go.id/resources/download/general/Hasil $\% 20$ Riskesdas\%202013.pdf

3. World Health Organization. Asthma. 2011 [cited2017 May 3]. Available from: http://www. who.int/mediacentre/factsheets/fs307/en/

4. Fitri R, Priyanto H, Rinanda T. Asthma Medication Adherence and Quality of Life in Persistent Asthma Patients. J Respir Indon. 2016;36(3):1307

5. Ramlie A, Soemarwoto R A S, Wiyoni W H. Korelasi antara Asthma Control Test dengan VEP1\% dalam Menentukan Tingkat Kontrol Asma. J Respir Indon. 2014;34(2):86-101.

6. Widysanto A, Surjanto E, Suradi, et al. Korelasi Penilaian Asma Terkontrol Pada Penderita Asma Persisten Sesudah Pemberian Kortikosteroid Inhalasi dengan Menggunakan Asthma Control Scoring System dan Asthma Control Test. J Kedokt Indon. 2009;1:56-63

7. McCoy EK, Thomas JL, Sowell RS, George C, Finch CK, Tolley EA, Self TH. An Evaluation of Peak Expiratory Flow Monitoring: A Comparison of Sitting Versus Standing Measurements. J Am Board Fam Med. 2010;23:166-7. doi: 10.3122/ jabfm.2010.02.090120

8. Atmoko W, Faisal HKP, Bobian ET, Adisworo MW, Yunus F. Prevalens Asma Tidak Terkontrol dan Faktor-Faktor yang berhubungan dengan tingkat kontrol Asma di Poliklinik Asma Rumah Sakit Persahabatan Jakarta. J Respir Indon. 2011; 31(2):53-60

9. Priyanto H, Yunus F, Wiyono WH. Studi Perilaku Kontrol Asma pada Pasien yang tidak teratur di Rumah Sakit Persahabatan. J Respir Indon. 2011;31(3):138-49

10. Lorensia A, Queljoe DD, Santosa KA. Kelengkapan Informasi Mengenai Cara Penggunaan Peak Flow Meter Yang Diberikan Kepada Pasien Asma di Apotek. Jurnal Ilmiah Manuntung. 2015;1(2):200-2

11. Sihombing $\mathrm{M}$, Alwi Q, Nainggolan O. Faktor Faktor Yang Berhubungan Dengan Penyakit Asma Pada Usia $\geq 10$ Tahun Di Indonesia. J Respir Indon. 2010;30(2):85-91.

12. Haryanti S, Ikawati Z, Tri M,et al. Hubungan Kepatuhan Menggunakan Obat Inhaler $\beta 2$-Agonis dan Kontrol Asma pada Pasien Asma. J Farm Klinik Indon. 2016; 5(4):238-48. DOI: 10.15416/ ijcp.2016.5.4.238

13. Behera SK, Patra SK, Saiprasanna B. A Study on Budesonide/ Formoterol vs. Fluticasone/ Salmeterol Inhaled Combination in Moderate to
Severe Asthma. J Pharm Biomed Sci. 2016;6:1249. doi: 10.20936/jpbms/160210

14. Jaeschke R, O'Byrne PM, Mejza F, et al The safety of long-acting beta-agonist among patients with asthma using inhaled corticosteroids: systematic review and metaanalysis. Am J Respir. 2008;178:1009-16. doi: 10.1164/rccm.2008044940C

15. Bachtiar D, Wiyono W H, Yunus F. Proporsi Asma Terkontrol di Klinik Asma RS Persahabatan Jakarta 2009. J Respir Indon. 2011;31(2): 90-100

16. Sheehan WJ, Phipatanakul W. Difficult to Control Asthma: Epidemiology and It's Link with Enviromental Factors. Curr Opin Allergy Clin Immunol. 2015;15(5):397-401. doi: 10.1097/ ACI.0000000000000195

17. William M, Tierney, Roesne F, et al. Assessing Symptoms and Peak Expiratory Rate as Predictors of Asthma Exacerbations. J Gen Intern Med. 2004;19:237-42. doi: 10.1111/j.15251497.2004.30359.

18. Ilyas M, Yunus F, Wiyono W H. Correlation between Asthma Control Test (ACT) and Spirometry as Tool of Assesing of Controlled Asthma. J Respir Indon. 2010;30:192-6.

19. Mendoza MR, Cruz BOD, Guzman-Banzon AV, et al. Comparative Assessment of Asthma control test (ACT) and GINA classification including FEV1 in predicting asthma severity. Philiphine: Heart Center and H.E.A.R.T Foundation Inc; 2007. p. 151-3

20. Departemen Kesehatan Republik Indonesia. Pharmaceutical care untuk penyakit asma. Jakarta: Departemen Kesehatan RI; 2007. 